\title{
ELIZABETH BISHOP, ARMÁRIO E GOZO: DINÂMICAS DO EROTISMO'
}

\section{ELIZABETH BISHOP, CLOSET, AND JOUISSANCE: DYNAMICS OF EROTICISM}

\section{Tiago Barbosa da Silva²}

RESUMO: Em carta e nos poemas $O$ banho de xampu e Canção do tempo das chuvas, Elizabeth Bishop (2006, 2011 e 2012) representa Key West, na Flórida, e a Casa de Samambaia, em Petrópolis, no Rio de Janeiro, retratando-os como lugares de maior acolhimento para sua subjetividade e sexualidade. Nesses textos, a poeta revela um jogo erótico com o lugar, dinamizado pelo soterramento de sua intimidade em descrições, aparentemente, neutras da realidade. Essa dinâmica sugere há existência de um jogo libidinal entre a insinuação de um segredo e, ao mesmo tempo, a manutenção de seu sigilo. Dona de uma poética do armário (SEDGWICK, 2007), Bishop, uma mulher lésbica, nesses textos, aponta para experiências íntimas, marcadas pela jouissance, pela relação erótica com o lugar (BATAILLE, 1987). Neste ensaio, proponho pensar esse jogo, destacando expressões de gozo simulacradas na relação com o ambiente, um gozo que se realiza à revelia da opressão, da hostilidade de gênero e do preconceito (LUGONES, 2019).

PALAVRAS-CHAVE: Elizabeth Bishop. Representações da Intimidade. Erotismo. Armário. Gozo.

ABSTRACT: In a letter and in the poems The Shampoo and Song for the Rainy Season, Elizabeth Bishop (2006, 2011, and 2012) represents Key West, Florida, and her house in Petrópolis, Rio de Janeiro, depicting them as zones of greater acceptance for her subjectivity and sexuality. In these texts, the poet reveals an eroticized dynamic with the idea of place, dynamized by the burying of her intimacy under apparently neutral descriptions of reality. This dynamic points to a libidinal urge between the hint of a secret and, at the same time, the maintenance of its secrecy. Owner of a poetics of the closet (SEDGWICK, 2007), Bishop, a lesbian woman, in these texts, points to intimate experiences, marked by jouissance (BATAILLE, 1987), by an erotic bond with place. In this essay, I discuss this dynamic, highlighting expressions of veiled jouissance, hidden underneath descriptions of the immediate space, which take place in spite of oppression, gender hostility and prejudice (LUGONES, 2019). KEYWORDS: Elizabeth Bishop. Representations of Intimacy. Eroticism. Closet. Jouissance.

\footnotetext{
${ }^{1}$ Artigo recebido em 14 de março e aceito em 18 de abril de 2021.

2 Professor Dr. do Instituto Federal de Sergipe (IFSE). Pós-doutorando no PPGL/UFS. Doutor em Letras pelo PPGL/UFPE (2018). Pesquisador associado ao Grupo de Estudos de Literatura e Crítica Contemporâneas (GELCCO), ao Grupo de Estudos sobre Representações, Alteridades e Subjetividades (ERAS), e ao Grupo de Pesquisa em Estudos de Texto, Leitura e Linguagem (GETELL). E-mail: tiagob_s@yahoo.com.br. ORCID: https://orcid.org/0000-0003-0615-9357.
} 


\section{Introduçầo}

Falar de sexualidade, de um modo mais direto, em Elizabeth Bishop, é uma tarefa quase impossível de ser realizada, já que a poeta, ao longo de sua vida, manteve um forte compromisso com o armário. A minha tese é que, inicialmente empurrada para esse lugar, Bishop o transforma, juntamente com a viagem e a errância, em posição primeira de articulação, de compreensão e de enunciação de suas experiências no mundo. Como ilustração dessa dinâmica do armário transformada em posição de enunciação, gosto de citar o caso, descrito no livro Remembering Elizabeth Bishop: An Oral Biography, de Fountain e Brazeu (1994), que documenta um desconforto entre Bishop e a também poeta Adrienne Rich, narrado por Richard Howard, amigo da primeira:

Adrienne Rich foi ver Elizabeth Bishop em Boston e tentou persuadi-la a ser mais direta sobre sua orientação sexual. Elizabeth não se mostrou favorável à empreitada. Depois da visita de Adrienne, eu me lembro dela descrevendo suas domesticidades em Lewis Wharf. "Você sabe o que eu quero, Richard? Eu quero armários, armários, e mais armários!" E gargalhou. ${ }^{3}$ (FOUTAIN e BRAZEAU, 1994, p. 330, tradução nossa).

Aparentemente consciente dessa dinâmica, como o evento acima sintetiza e sugere, em seus poemas, sua presença é sentida não de forma explícita, mas de um modo sorrateiro, sem anúncio, misturando-se, pelas frestas, aos objetos e à paisagem que descreve - Elizabeth Bishop, portanto, fala de dentro do armário. Há, desse modo, uma espécie de simulacro em seus textos, uma mecânica do fingimento, termo que a poeta utilizou em 1934, em texto republicado no livro Edgar Allan Poe and The Juke Box (2006), para descrever a obra do poeta inglês W. A. Auden. Nessa mecânica, segundo a própria poeta, há uma ocultação, pelo soterramento de traços biográficos e de significados mais profundos e íntimos em descrições objetivas, aparentemente superficiais de dados da realidade. Existe, assim, um

\footnotetext{
${ }^{3}$ Adrienne Rich had been to see Elizabeth Bishop in Boston and had attempted to persuade her to be more forthcoming about her sexual orientation. Elizabeth did not regard the enterprise with favor. After Adrienne's visit, I remember her describing her new domesticities at Lewis Wharf. "You know what I want, Richard? I want closets, closets, and more closets!" And she laughed.
} 
conteúdo implícito em seus textos que precisa ser desenterrado, escavado de descrições articuladas em função da falsa ideia de neutralidade e da ocultação de traços de sua subjetividade e de suas experiências, que guiam a elaboração de seu trabalho poético e também o modo como fala de sua intimidade, de sua vida privada, de si, e também o jeito como se coloca em relação com o outro e com o mundo.

Assim, a sexualidade em Bishop se revela pela sua ocultação, pelo seu apagamento da camada mais externa do texto poético e soterramento em camadas mais profundas de processamento dos sentidos - a sexualidade em Elizabeth Bishop, em seus textos, é um vestígio, quase não existe, embora vibre disfarçadamente em tudo. Bishop, publicamente, não sentia que podia existir como lésbica e parece que esse traço de sua experiência a motivou, também, a buscar, incessantemente ao longo da vida, espaços menos hostis para ser/viver/existir, transformando o lugar, metaforizado na casa, em um objeto libidinal, com o qual experimenta uma relação fronteiriça entre dor e prazer. Essa característica de seu trabalho resulta de confrontos com o entendimento de gênero e com a heteronormatividade encontrados nos lugares nos quais viveu (LUGONES, 2019), que a forçaram a desenvolver estratégias de sobrevivência e de realização de seu desejo não aceito, impondo-a um silenciamento para o qual a poeta encontra, no disfarce, formas de se expressar, conviver e também de resistir.

Dessa maneira, as mulheres com as quais se relacionou são, geralmente, descritas como amigas e aparecem, somente de relance. Elas se transformam em friends, em suas cartas, e em the joking voice, em seu poema mais famoso, One Art. Suas mulheres são escondidas por detrás de palavras que amenizam suas importâncias ou dessexualizam suas existências. Seu gozo, por outro lado, aparece projetado nos lugares, nos fragmentos do espaço pelos quais transitou, misturando-se com plantas, mofos, líquens, animais, bem como com a arquitetura e a paisagem, sinalizando um movimento de entrada no mundo e de desfazimento de suas próprias fronteiras.

A ocultação de si mesma em seu trabalho não acontece somente no que diz respeito a sua sexualidade, como discuti no livro O não-lugar em Elizabeth Bishop (SILVA, 2018). Forjada em contato com um mundo hostil, em contextos patriarcais, num 
mundo que tiraniza mulheres, Bishop dizia resistir com um feminismo próprio: "uma sensação de estranhamento irremediável do mundo" 4 (MILLIER, 1993, p. 23, tradução nossa). De certo modo, na representação do lugar como objeto de gozo, Bishop pode ter encontrado uma forma de dar vazão ao seu desejo, de expressá-lo, aceitando o seu exílio no armário, mas rebelando-se contra sua força esterilizante. Assim, ela assegura a sobrevivência de seu desejo, encontrando o gozo também fora do espaço habitado, no encontro com a possibilidade de outras relações - uma "que não Ihe retorne o vazio, tal como ocorre quando o desejo está orientado para a destruição" (Marín-Dòmine, 2015, p. 105), padrão geralmente presente em relações antagônicas que não se voltam para o reconhecimento de um sujeito no outro, mas para a dominação e para o controle.

Essa alteração do objeto libidinal em suas representações, portanto, é fruto de um cotidiano «submetido à banalização do sentido humano" (CARLOS, 2007, p. 39), que coloca "o homem como o ser humano por excelência", diz María Lugones (2019, p. 359), em seu ensaio Rumo a um feminismo decolonial, aprisionando as mulheres em padrões que a posicionam como o inverso do standard de excelência. Num ato de resistência, portanto, Bishop mistura experiências, manejando o meio a partir da aproximação do inexplorado ou do estranhamento do conhecido, de sua recusa, insistindo na gestação de uma localização, de uma experiência e de um prazer próprios, que lhe garantam a possibilidade de continuar existindo.

\section{Viver no armário: mecânicas do fingimento}

Ainda jovem, no período em que viveu em Key West, na Flórida, por exemplo, Bishop relata, em carta para a poeta Marianne Moore, escrita em janeiro de 1938, os hábitos das pessoas e seu novo cotidiano, destacando os costumes dos donos e hóspedes da pensão onde estava hospedada. A Sra. Pindar e o marido, por exemplo, "São muito religiosos e cantam hinos de igreja o dia inteiro, e aos domingos ficam em suas cadeiras de balanço na varanda junto à minha janela e têm longas conversas sérias

${ }^{4} \mathrm{~A}$ feeling of irremediable estrangement from the world. 


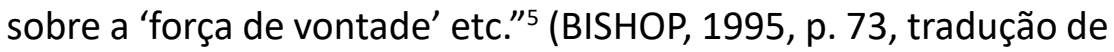
Brito). Além deles, "Tem um outro 'inquilino' também, um certo senhor Gay, a respeito de quem estou gradualmente escrevendo um conto. O quarto dele é cheio do que ele chama de 'novidades,' as quais ele guarda em caixas de charuto: são folhas e vagens etc." ${ }^{1}$ Nesse lugar, as flores têm todas nomes violentos: "ele acaba de me dar uma 'rosa-do-inferno,' e tem também 'língua-de-muIher,' 'coroa-de-espinhos' etc. - esta última é uma planta muito estranha; vou tentar levar uma para lhe mostrar."7 Mesmo tentada a postar amostras desse material para a amiga, a poeta hesita: "meu quarto está começando a ficar com um aspecto pouco saudável de tão cheio que está dessas coisas, de modo que vou poupá-la." ${ }^{8}$ Essa constatação bem como a necessidade de ocultar certas coisas não parecem representar um problema para a jovem poeta, em cuja carta o tom predominante é o contentamento e a alegria, liberados por esse novo lugar.

Na carta, há uma ideia de 'imundície', palavra que, formada pela junção do prefixo in-, que pode significar movimento para dentro, à raiz mundus, relacionada à palavra mundo, sugere um movimento de entrada no próprio mundo. A insalubridade do quarto - sua imundície -, aponta para uma 'sujidade' no que há de mais íntimo no espaço privado de uma pessoa, cria uma imagem de mistura, de contato com o mundo, de baldeamento não só do espaço físico, mas da intimidade, sugerindo que a poeta, forjada em um contexto extremamente conservador, sentia-se suja ou em um ambiente sujo, mas ao mesmo tempo bem, em um sútil êxtase; tocada pelo outro, contaminada pela vida, dentro do mundo. No movimento de deslocamento espacial, nesse caso, do norte dos Estados Unidos, onde vivia em Nova lorque, para o sul do país, em Key West, na Flórida, onde viveria sua primeira relação amorosa duradoura, Bishop parece encontrar a chave para manipular seu desejo, percebendo que é esse colocar-se em relação, esse

\footnotetext{
${ }^{5}$ They are very devout people and sing hymns all day long and on Sundays they sit rocking on the verandah outside my window and have long solemn conversations about 'willpower,' etc.

${ }^{6}$ There is another 'roomer,' a Mr. Gay, who I am gradually writing a story about. His room is filled with what he calls 'novelties,' which he keeps in cigar boxes; they are all leaves and seed pods, etc. he just gave me a 'Rose of Hell,' and there are 'Woman's tongue,' 'Crown of Thorns,' etc. - the last is a very strange plant; I shall try to bring one back with me to show you.

${ }^{7}$ he just gave me a 'Rose of Hell,' and there are 'Woman's tongue,' 'Crown of Thorns,' etc. - the last is a very strange plant; I shall try to bring one back with me to show you.

${ }^{8}$ my own room is beginning to look so unhealthy with them that I shall spare you.
} 
desfazer-se de suas próprios fronteiras, simbólicas e espaciais, esse tornar-se dentro do mundo, que dinamizaria, eroticamente, sua experiência, atribuindo, dessa maneira, à relação com o lugar, um caráter libidinal, uma espécie de força vital mobilizadora, razão de seu próprio trânsito, de sua movência no mundo.

De qualquer forma, como também sugere na carta, esses sinais de transcendência erótica, de realização do desejo sexual, não deveriam ser alardeados, mas guardados em caixas, empacotados, como a folha da língua-de-mulher, a rosa do inferno, as ostras e as conchas que achava em Key West, demonstrando que sua mecânica do fingimento, sua relação subjetiva com o armário, era também estratégia de sobrevivência em ambientes adversos, que negavam sua existência enquanto mulher lésbica; era também um jeito de realizar-se sem contrapor, frontalmente, as estruturas machistas da sociedade nem o silenciamento de sua experiência. Assim, ressabiada pela vivência em um mundo de violências misóginas, para proteger-se, Elizabeth Bishop camufla seu desejo no encontro com o mundo.

Pelo tom predominante na carta citada anteriormente, Bishop sentia-se também feliz, sentia-se mais livre, como alguém que retira de si o peso de ser quem se é e é simplesmente. É-se mulher, lésbica. É-se. Partindo de George Bataille (1987), em seu livro $O$ Erotismo, o ingresso e o seu reestabelecimento em outra parte do espaço, em um novo 'lugar', revela a aspiração de se perder através de jogos de equivalências e trocas entre os sistemas. Em outros termos, Bishop, falando do lugar, abre a cortina de uma pequena janela para que possamos ver sua vontade de entrar em contato, de dançar com outro, de colocar-se em relação, numa relação de gozo, de juissance, de busca de uma continuidade perdida, de uma expansão de si através do contato "aprovando a vida até na morte," diz Bataille (ibid., p. 10), entre folhas secas, restos de plantas, conchas abandonadas (BISHOP, 1995, tradução de Brito), dentro da sujidade do mundo. O erotismo, assim, é o cruzamento de uma fronteira, do rompimento com uma ordem que regia seu corpo e o confinava em padrões artificializados, é o desejo de desmanchar o outro e desmanchar-se, em outro, novo, é a vontade de entrar em comunhão com outros seres.

No movimento de desintegração e reintegração de seus limites que esse erotismo gera, diferentes sistemas simbólicos se 
fundem, concretizando uma "destruição da estrutura do ser fechado que é, no estado normal, um parceiro do jogo." (BATAILLE, 1987, p. 10). No encontro com o lugar desconhecido, há gozo, há a gestação de prazer, um encantamento sutil que recobre todo o texto, desvelando uma dinâmica libidinal e, ao mesmo tempo, dando vazão e soterrando, textualmente, vivências mais íntimas, mais sexuais, mais subjetivas, embaixo de coisas, de lugares, etc. Em outros termos, acostumada a lugares nos quais vivia em contato permanente com dispositivos de regulação de sua sexualidade (SEDGWICK, 2007), no novo lugar, Bishop se sente mais livre, mais disponível para explorar seu desejo, mas, mesmo assim, ainda impossibilitada de falar diretamente sobre suas vivências, particularmente em textos, como o da carta, endereçados à antiga realidade, ou em poemas, produzidos para o público da elite estadunidense e de poetas nova iorquinos, pouco abertos, no período, para essas explorações.

Para Sedgwick (2007), o armário, no século XX, é marco da experiência de gays e lésbicas nos Estados Unidos, já que "num nível individual, até mesmo as pessoas mais assumidamente gays", o que não é o caso da poeta, como sinaliza a anedota do armário, mencionada no começo deste ensaio, "há pouquíssimas que não estejam no armário com alguém que seja pessoal, econômica ou institucionalmente importante para elas" (ibid., 2008, p. 23). Essa experiência estabeleceria uma dinâmica subjetiva na qual o sujeito oscila entre oposições "privado/público, dentro/fora, sujeito/ objeto" (MILLER, D. A. apud SEDGWICK, 2007, p. 21), mantendo, teoricamente, a inviolabilidade de cada um dos primeiros termos desses binarismos.

Nesse sentido, o armário surge como modo de proteger-se do "escrutínio insultuoso, contra a interpretação forçada de seu produto corporal", para que se "possa escolher deliberadamente entre ficar ou voltar para o armário em algum ou em todos os segmentos de sua vida" (SEDGWICK, 2007, p. 22). Assim, o armário se converte em "característica fundamental da vida social, e há poucas pessoas gays, por mais corajosas e sinceras que sejam de hábito, por mais afortunadas pelo apoio de suas comunidades imediatas, em cujas vidas o armário não seja ainda uma presença formadora" (idem., 2007, p. 22), codificando "um torturante sistema de duplos vínculos, oprimindo sistematicamente as pessoas, identidades e 
atos gays ao solapar, por meio de limitações contraditórias ao discurso, as bases de sua própria existência" (idem., 2007, p. 26).

Dessa maneira, por um lado, o armário funciona enquanto estratégia de sobrevivência; é uma epistemologia, um saber produzido em uma realidade avessa ao homoerotismo que torna a vida de algumas subjetividades LGBTQIA+ possível. Por outro lado, ele pode autorizar o insulto e gerar mais insegurança, produzindo "relações cuja utilidade faz parte da ótica do assimétrico, do especular e do não explícito" (idem., 2007, p. 38), transformando a existência no armário, embora supostamente segredada e protegida, em algo volátil e violento, disruptivo e instável, prestes a sempre-e-nunca implodir, desestabilizando as geografias subjetivas, pessoais e políticas, e as relações dos sujeitos com outras pessoas.

A partir da carta em destaque, pode-se realizar uma espécie de arqueologia dos nomes das pessoas mencionadas, possivelmente 'personagens' de Bishop, e pode-se ler as referências pensando-se na dinâmica do armário, em como esse texto indicia sua percepção da sexualidade e da liberação do peso de ser lésbica em um contexto hostil. Nesse sentido, desenterrando o que há soterrado no texto, escondido dentro do armário, a senhora Pindar pode ser uma referência ao poeta grego Pindar, de Thebas, que proferiu a famosa frase "Homem, torna-te o que és", sugerindo que Key West era também um espaço onde podia ser quem era.

Além disso, a outra 'personagem' do fragmento, um certo senhor Gay, pode ser um alter ego, uma persona criada pela poeta para falar de si mesma, já que os comportamentos dele, sua obsessão com as folhas e coleção de coisas estranhas, são os mesmos comportamentos que a poeta adota nesse novo contexto. Estratégia similar foi utilizada por Bishop (2006) em seu primeiro poema, I introduce Penelope Gwin, escrito quando ainda era menina. Nele, o sobrenome Gwin sinaliza desencaixe e, possivelmente, uma percepção de sua própria sexualidade, já que, como observa Quinn (2007), a palavra é muito semelhante ao termo francês gouine, uma gíria para lésbica, comum entre mulheres que se travestiam nos anos 1920.

Na lógica do fingimento, Bishop fala de Key West, inicialmente, como um lugar lúbrico, livre, que lhe permitiria manter contato, entrar em relação, bem como conhecer coisas com nomes esquisitos, como a planta língua-de-mulher e esconder suas 
folhas em caixas, como se fossem segredos. No trânsito, Bishop escapa, temporariamente, da presença asfixiante do armário, colocando-se em uma outra espacialidade, mais licenciosa. Sua mudança, de Nova York para Key West, neste caso, onde viveu sua primeira relação amorosa duradoura, pode ter sido processada pela poeta, como sugere a carta em questão, dentro da lógica do fingimento, sendo traduzida, assim, a partir de um jogo voluptuoso com o lugar, no contato, no estabelecimento de relações mais livres, metaforizadas em seu encontro com o mundo e com o lugar. A busca por lugares assim, frestas no espaço que pudessem ser penetradas e descobertas lenta e prazerosamente, atravessa a trajetória da poeta e é reencenada muitas vezes em sua vida.

Ao falar de forma tão velada de si, Bishop apaga sua sexualidade de tudo, mas simultaneamente permite que tudo, inclusive seu trânsito no mundo, seja pensado enquanto dinâmica do desejo, enquanto jogo erótico, enquanto vivências de sexualidade/ sensualidade. A viagem e a mudança em Bishop evidenciam, portanto, também um jogo libidinal, que sensualiza seu cotidiano, incitando prazeres e a sensualização da vida, dando vasão ao gozo, mesmo que em segredo, que no armário, mesmo que através do contato volúvel com lugares desconhecidos.

\section{0 jogo erótico com o lugar}

Esse jogo erótico com o lugar pode ser reencontrado em poemas nos quais Elizabeth Bishop reconstrói fragmentos da espacialidade Brasil - onde passou a viver no começo da década de 1950 -, e de seu espaço privado/íntimo neste país. Em The Shampoo, traduzido por Paulo Henriques Britto, como $O$ banho de Xampu, publicado originalmente em A Cold Spring, os líquens, formados pelo encontro de fungos e algas, crescem silenciosos, avançando nas pedras, em direção aos anéis luminosos em torno da lua. Essa experiência-encontro é constituída por pequenos choques concêntricos, talvez uma referência ao movimento espermático dos músculos no orgasmo:

Os liquens - silenciosas explosões nas pedras - crescem e engordam, concêntricas, cinzentas concussões. 
Têm um encontro marcado

com os halos ao redor da lua, embora

até o momento nada tenha se alterado.

(BISHOP, 2012, p. 213, trad. de Paulo Henriques Britto).

Esta primeira estrofe do poema menciona um tipo de associação biológica de longo prazo, vivida entre organismos de diferentes espécies - a simbiose -, que geralmente é benéfica para os seres envolvidos. Em uma interação assim, como a dos liquens, os organizamos se integram, borrando suas fronteiras, perdendo seus contornos e definições. Um penetra o outro, adentra seu simbionte de modo que é quase impossível saber qual é qual. Nesse movimento de integração, que constitui a própria relação, nesse encontro marcado, algas e fungos viabilizam a própria vida, tornando seu existir mais fluido, num vínculo entre diferentes que traz, simultaneamente, proteção e alimento, permitindo seu crescimento, sua explosão sobre as pedras, sua multiplicação e 'fertilidade', pensadas aqui não como reprodução, mas como ambiente propício a vida, a sensações, a percepções dos sentidos. $\mathrm{Na}$ terceira e última estrofe do poema, os cabelos da dear friend, mencionada antes no poema, são observados pela enunciadora:

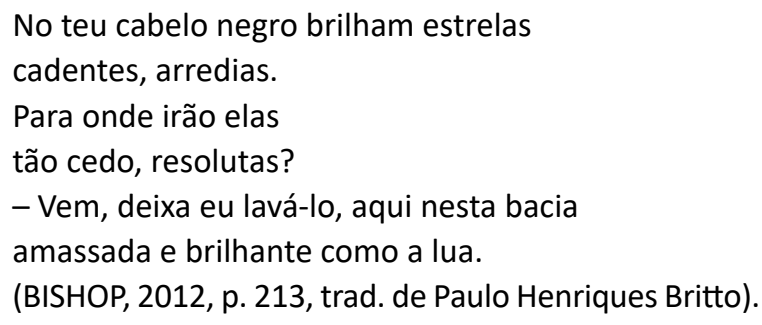

Com gênero indefinido, já que dear friend pode ser qualquer homem ou mulher, os fios brancos de seu cabelo são transformados em estrelas cadentes, arredias, sem rumo certo, que serão banhados, molhados, fluidificados pelas mãos da amiga/ enunciadora do texto. No poema, a pessoa de quem fala - Lota de Macedo Soares, com quem Bishop viveu uma relação de mais de quinze anos -, é escondida debaixo desse termo genérico, que não nega sua importância, mas não a revela, mantendo o segredo ocultado, dentro dos elementos da paisagem, entre fungos e algas, enquanto as amantes se banham em uma bacia amassada, brilhante como a própria lua. De qualquer forma, o contato visual 
entre a enunciadora e sua amante é responsável por uma desorientação naquela, uma espécie de desnorteamento temporário, mais evidente nos versos em inglês, que a faz questionar o sentido, a objetividade e a brevidade das coisas e experiências.

Já em Canção do tempo das Chuvas, também traduzido por Paulo Henriques Britto, publicado no livro Questões de Viagem, a casa de Samambaia, onde viveu em Petrópolis, é construída, novamente, como um lugar em que seres de diferentes naturezas se encontram, ocultamente, em uma atmosfera nebulosa, úmida, fluídica. A casa é aberta e se integra com a natureza que a circunda. Ela é penetrada pelas nuvens, enquanto as bromélias sujam as pedras como se fossem sangue, e as cascatas e os líquens se aproximam como se fossem íntimos. A água, o gozo, jorra. O riacho canta de dentro da caixa torácica, por dentro da mata grossa, fazendo subir um vapor que envolve tudo em uma atmosfera própria, em uma nuvem só delas, íntima, secreta e aquosa. A casa é um lugar úmido, tão úmidos que mesmo à noite gotas se formam e escorrem pelo seu telhado, como se estivesse envolvida em um ato sexual. Nela, pererecas gordas coaxam por amor em plena cópula:

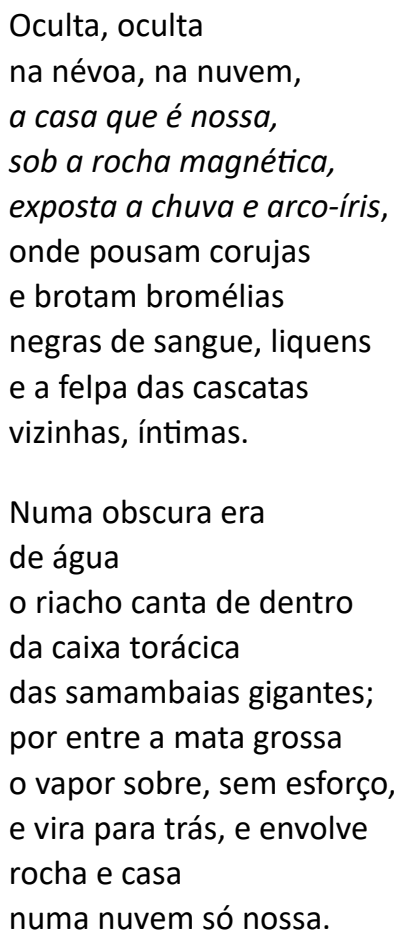




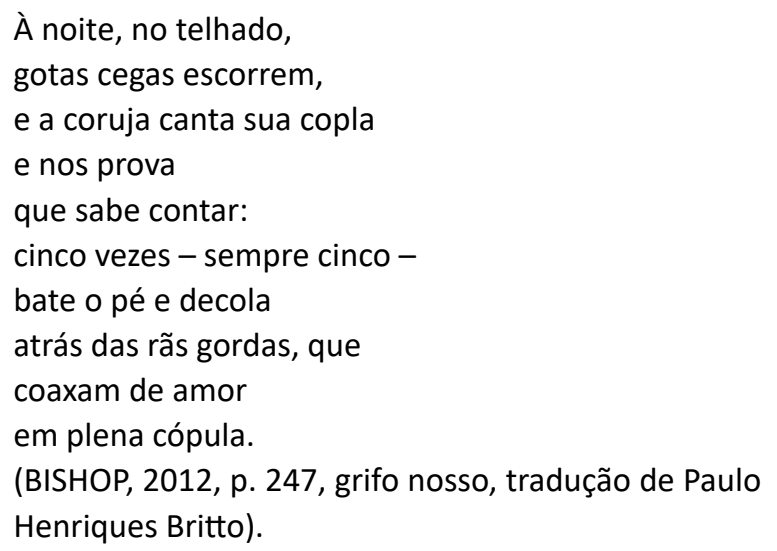

Nos versos em destaque no poema, a casa onde vivem está sob a pedra, num estado de quase êxtase, de ligação e transformação, evidenciado pela palavra rain- hifenizada que se transforma, a partir da junção com -bow, logo em seguida, em arco-íris, sugerindo uma profusão de cores, um jorro de sensações visuais. Curiosamente, a casa é rainbow-ridden, ou seja, montada, cavalgada pelo arco-íris, enquanto plantas, animais e o ruído da água da cachoeira se agarra a ela. A casa, de novo, é aberta, para o orvalho branco, para o gozo, e o amanhecer tem cor de leite, adocicado para o olhar, para o convívio com a lesma, com traça e camundongo, e com grandes borboletas, com paredes sujas de bolor, para a exuberância da festa que é a natureza:

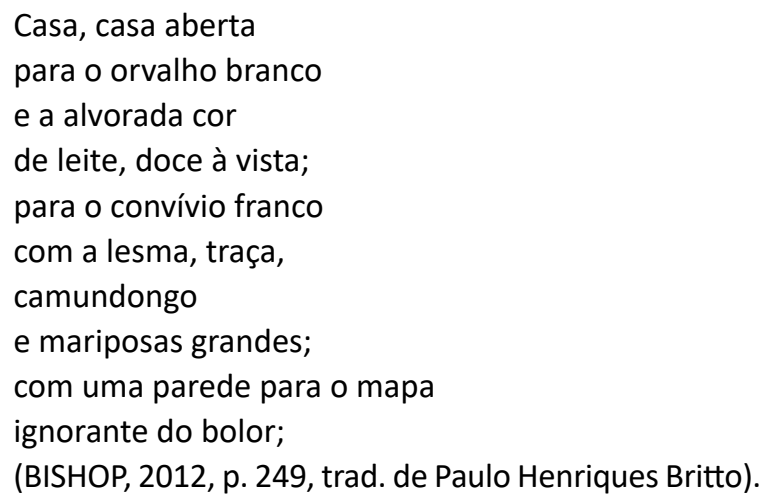

No poema em inglês, o verso "para o convívio franco" da tradução de Britto é, na verdade, "to membership", sugerindo pertencimento e convite a uma estadia prazerosa, já que o verbo em questão poderia ser traduzido como filiar-se ou associar-se, fazer- 
-se pertencer a esta casa, mais uma vez, no in-mundus, dentro do mundo, junto com seres de diferentes tipos: insetos, peixinho-de-prata, traças e mariposas; fungos e roedores. É interessante observar ainda a menção ao mofo na parede em formato de mapa, referência frequente no trabalho de Bishop: este mapa, no entanto, destoa dos outros por ser ignorante, por não demonstrar caminho, nem rumo certo, por não organizar a realidade, insinuando vontade de permanecer, perda do controle, satisfação e completude, sentimentos raros nos textos da poeta, característicos do gozo, segundo George Bataille (1987). Mesmo apartada das pessoas, como o poema sugere, o eu lírico entra em comunhão com o mundo, com fauna e flora, entra em uma relação e em uma vivência compartilhadas com outros seres, encontrando validação e reconhecimento, na experiência biótica, no estar viva, no ser, simplesmente ser como os outros seres do mundo.

\section{Consideraçồes finais}

Em alguns de seus textos, Elizabeth Bishop deixa entrever uma zona de contato erotizada entre si e o outro, entre si e muIheres com as quais se relacionou, dissimulada no seu encontro e vivência com o lugar, com a casa. Escavando o que há em camadas mais profundas de sentido em seus textos, pode-se pensar neles como representações simulacradas do seu desejo e do seu gozo, de um jogo erótico denegado, desenvolvido para viabilizar sua existência em contato com dispositivos de controle de sua sexualidade e, ainda assim, vivê-lo - viver o desejo e a realização sexual mesmo que impossibilitada de falar abertamente deles. Dessa maneira, ao mesmo tempo em que adequada seus textos às exigências da heteronormatividade compulsória, que coloniza os nossos corpos (LUGONES, 2019), Bishop encontra estratégias de comunicação, cifradas, de sua vivência enquanto mulher e lésbica. Logo, seus textos revelam a existência de uma dinâmica do armário, representando, simultaneamente, submissão e transgressão, objetividade e subjetividade, negação e afirmação do desejo, entrelaçando sua experiência com a experiência, contemporânea, de outras subjetividades LGBTQIA+ e seres.

Nesse processo de esconder e revelar, Elizabeth Bishop quebra os limites entre o humano e a natureza, entre os reinos 
animal e mineral, tornando-os todos penetráveis e penetrantes, em contato prazeroso e em sútil êxtase, num fluxo de significação que transcende as fronteiras estabelecidas e irrompe em ambivalências, contradições, criando fragmentos de espaços erotizados, sensualizados - lugares transantes, que experimentam o prazer e a dor de viver em relação. Nesse sentido, em seu movimento no mundo e na relação representada com os lugares onde permaneceu, notadamente Key West e Petrópolis, a poeta se liberta, parcialmente, da sua posição, do seu lugar de enunciação - o armário, onde encontrou uma posição de enunciação, e ingressa num mundo novo, desorganizado, abandonando-se na extrapolação de seus limites, pondo-se em contato com outros organismos e dentro do mundo. Há, em seus textos, portanto, a representação de atos do desejo, "da vontade de integrar-se ao outro separado, e reconstitui-se, principalmente, a partir da demanda de diluir o outro" (SILVA, 2019, p. 165), de misturar-se com o mundo, sucumbindo, eventualmente, à incompletude da experiência, fazendo surgir o desejo de expandir-se, no contato com o outro, de novo e de novo.

\section{Referências}

BATAILLE, G. O Erotismo. Porto Alegre: L\&PM, 1987.

BISHOP, E. Edgar Allan Poe and the Juke-Box: uncollected poems, drafts, and fragments. Nova lorque: Farrar, Straus and Giroux, 2006.

BISHOP, E. Poems: Elizabeth Bishop. New York: Ferrar, Straus and Giroux, 2011.

BISHOP, E. Poemas Escolhidos de Elizabeth Bishop. Seleção, Tradução e Textos Introdutórios de Paulo Henriques Britto. 1. ed. São Paulo: Companhia das Letras, 2012.

BISHOP, E. Uma Arte: as cartas de Elizabeth Bishop. Tradução de Paulo Henriques Britto. São Paulo: Companhia das Letras, 2012.

CARLOS, A. F. A. O lugar no/do mundo. São Paulo: FFLCH, 2007.

FOUNTAIN, G. e BRAZEAU, P. Remembering Elizabeth Bishop: An Oral Biography. Amherst: University of Massachusetts Press, 1994. 
LUGONES, M. Rumo a um feminismo decolonial. In: HOLLANDA, H. B. (Org.). Pensamento Feminista: Conceitos Fundamentais. Rio de Janeiro: Bazar do Tempo, 2019.

MARÍN-DÒMINE, M. Traduzir o Desejo: Psicanálise e linguagem. Belo Horizonte: Editora UFMG, 2015.

MILLIER, B. C. Elizabeth Bishop: life and the memory of it. Berkeley: University of California Press, 1993.

SEDGWICK, E. K. A Epistemologia do Armário. Cadernos Pagu, Campinas, UNICAMP, vol. 28, jan./jun., p. 19-54, 2007.

SILVA, T. B. O não-lugar em Elizabeth Bishop. Aracaju: EDIFS, 2019. 